\title{
New disinfectants for inactivation and disinfection of Pseudomonas aeruginosa: comparison with market leaders
}

\begin{abstract}
Background: Hospital-acquired infections are a major global burden that is largely preventable. Strict cleaning protocols and effective disinfectants are essential standard practice in healthcare settings to prevent the spread of pathogens. Nevertheless, one in twenty-five hospital patients experience at least one healthcare-associated infection.

Methods: The bactericidal efficacy of four disinfectants was tested against Pseudomonas aeruginosa using the AOAC use-dilution test. Two glutaraldehyde-based products, Microbide-G and Cidex Plus ${ }^{\mathrm{TM}}$ 28, were directly compared, and two ortho-phthalaldehydebased products, Microbide-O and Cidex ${ }^{\circledR} \mathrm{OPA}$, were similarly tested. The difference between the tested agents is the micellar nature of the disinfectant in the Microbide products. All disinfectants were tested with various contact times and at two temperatures.

Results: At $20^{\circ} \mathrm{C}$, Microbide-G was the only product to achieve full disinfection after three minutes of contact time, while Cidex Plus ${ }^{\mathrm{TM}} 28$ failed up to eight minutes of contact time. Microbide-O passed after five minutes of contact time, whereas Cidex ${ }^{\circledR} \mathrm{OPA}$ did not. At $45^{\circ} \mathrm{C}$, all products performed better, but the Microbide products required less time of exposure compared to those of Cidex.
\end{abstract}

Conclusion: The results indicate that Microbide- $\mathrm{G}$ and Microbide-O display greater efficacies than the current commercial products for successful elimination of $P$. aeruginosa. Furthermore, the micellar nature of the Microbide products reduces volatility of the active components, decreasing respiratory exposure.

Keywords: hospital-acquired infection, Pseudomonas aeruginosa, disinfectant, AOAC use-dilution test, Microbide, Cidex
Volume 7 Issue 3 - 2019

\author{
Lukyn M Gedge, 'Angela L Hollingsworth, ${ }^{2}$ \\ Donna B Suchmann² \\ 'Microbide Limited, Ireland \\ ${ }^{2}$ Microbac Laboratories, Inc. USA
}

Correspondence: Lukyn M Gedge, Microbide Limited, Ireland, Email lukyn.gedge@microbide.com

Received: May 15, 2019 | Published: May 27, 2019

\section{Background}

Pseudomonas aeruginosa is a clinically relevant opportunistic pathogen that is a major cause of nosocomial infections worldwide. The bacterium's ubiquitous nature predominantly affects those with compromised host or mucosal immunity with a wide range of presentations including pneumonia, endocarditis, peritonitis, meningitis, bacteremia, and overwhelming septicemia. Routes of transmission in healthcare settings include water sources such as medical tubing ${ }^{1}$ or cross-infection through contaminated medical diagnostic or surgical devices, such as endoscopic equipment. ${ }^{2-5}$ In the US, an estimated 51,000 healthcare-associated $P$. aeruginos $a$ infections occur per year with more than 6,000 multidrug-resistant cases causing approximately 400 deaths. ${ }^{6}$ The bacterium habitually adopts a sessile biofilm lifestyle that is resistant to antimicrobial management. ${ }^{7}$ Surveillance of these infections has shown trends in increasing antimicrobial resistance due to a combination of the bacterium's inherent resistance to many drug classes, its ability to acquire resistance via mutations to new treatments, its high prevalence, and its recurrent role in severe infections. ${ }^{8}$ Therefore, prevention of $P$. aeruginosa infection by disinfection interventions that eradicate bacteria is essential to interrupt the pathogen's spread. The Centers for Disease Control and Prevention (CDC) formulated Guidelines for Disinfection and Sterilization in Healthcare Facilities. ${ }^{9}$ Both the CDC and the Environmental Protection Agency (EPA) recommend using disinfectant products that comply with these guidelines. However, some of these require a full twelve minutes of contact time to for full disinfection. ${ }^{10}$ This long contact time is often difficult to achieve in a healthcare environment due to time pressure. For practical usage, disinfectants should cause a significant reduction in pathogen viability on environmental surfaces (fomites) following a reasonably short contact time under ambient conditions. It is widely accepted that efficacy testing of disinfectants is best performed in carrier studies rather than in suspension studies. ${ }^{11,12}$ The gold standard for testing the antimicrobial efficacy of liquid disinfectants on fomites is the Use-Dilution test designed by the Association of Official Analytical Chemists (AOAC). ${ }^{13}$ This test is specified by the U.S. EPA as the required method for validating a hospital disinfectant claim. ${ }^{14}$ The Use-Dilution method is conducted by soaking stainless steel carriers in $P$. aeruginosa bacteria, treating the carriers with the disinfectant, and then placing the carriers in growth broth containing neutralizer to establish whether any surviving bacteria remain.

Abbreviations: ATCC, American type culture collection; AOAC, association of official analytical chemists; CDC, centers for disease control and prevention; EPA, environmental protection agency; MRC, minimum recommended concentration; NB, nutrient broth; NA, nutrient agar; TSA, tryptic soy agar; NHS, United Kingdom's national health service 
In this study, we have evaluated the comparative efficacy of four disinfectants against $P$. aeruginosa using the well established AOAC Use-Dilution test. The surface inactivation efficacies of two proprietary micellized aldehydes (Table $1 \&$ Table 2) from Microbide Limited (Microbide ${ }^{\mathbb{Q}}-\mathrm{G}$ and Microbide ${ }^{\mathbb{}}-\mathrm{O}$ ) were compared with the market-leading Cidex products (Cidex Plus ${ }^{\mathrm{TM}} 28$ and $\mathrm{Cidex}^{\circledR}$ OPA) from Johnson \& Johnson. Micellization is a naturally occurring dynamic process during which amphipathic molecules form multimolecular structures in aqueous solution. Micelles assume spherical, cylindrical, or ellipsoid shapes, among others. Micellization occurs when surfactants - for example, detergents or oil - are suspended in polar liquids such as water at concentrations exceeding the critical micelle concentration. The amphipathic molecules assembled in the micelle remain in equilibrium with monomeric molecules in the fluid.

Table I pH of evaluated products

\begin{tabular}{|c|c|c|}
\hline Product & Active Component & $\begin{array}{l}\text { pH of Undiluted } \\
\text { Formulation }\end{array}$ \\
\hline Cidex Plus $^{\mathrm{TM}} 28$ & $3.4 \%$ glutaraldehyde & 7.7 \\
\hline Microbide ${ }^{\circledR}-G$ & $3.0 \%$ micellar glutaraldehyde & 6.4 \\
\hline Cidex ${ }^{\circledR}$ OPA & $0.55 \%$ ortho-phthalaldehyde & 7.3 \\
\hline Microbide ${ }^{\circledR}-\mathrm{O}$ & $\begin{array}{l}0.55 \% \text { micellar ortho- } \\
\text { phthalaldehyde }\end{array}$ & 6.8 \\
\hline
\end{tabular}

\section{Materials and methods}

\section{Micellization of aldehydes}

The disinfectants glutaraldehyde and ortho-phthalaldehyde were suspended in aqueous solvent at concentrations exceeding the critical micellar concentration. Micelle formation was characterized by time-of-flight gas chromatography/mass spectrometry (GC/MS). Comparison of GC scans of the aldehydes before and after undergoing Microbide's patented process showed successful micellization.

\section{Disinfectant preparation}

Each test agent (disinfectant) was prepared as required by the label instructions. The disinfectants were artificially stressed with the addition of fetal bovine serum to yield a $2 \%$ organic load. On the day of the test, each disinfectant was evaluated according to standard operating procedures to assess the concentration of the active ingredients. Based on that result, dilutions were prepared using $400 \pm 12 \mathrm{ppm}$ hard water $^{15}$ Cidex Plus ${ }^{\mathrm{TM}}$ 28(3.4\% glutaraldehyde) and Microbide $^{\circledR}-\mathrm{G}$ (3.0\% micellar glutaraldehyde), were diluted to a minimum recommended concentration (MRC) of 14,000-15,000ppm (1.40-1.50\%) active. Cidex ${ }^{\circledR}$ OPA $(0.55 \%$ ortho-phthalaldehyde) and Microbide ${ }^{\circledR} \mathrm{O}$ (0.55\% micellar ortho-phthalaldehyde), were diluted to an MRC of 2,800-3,000ppm (0.28-0.30\%) active. A confirmatory analysis was performed to ensure the correct MRC had been reached. The $\mathrm{pH}$ of each diluted disinfectant was also determined. Once confirmed, each disinfectant was dispensed in $10 \mathrm{~mL}$ aliquots into sterile test tubes. The tubes were allowed to come to the appropriate test temperature for at least ten minutes before testing. All aspects of the test (and control) phases involving the disinfectants were performed within 3hours of the completion of its preparation. Table 2 shows the exact information for each lot of the products used in this study.

\section{Inocula preparation}

P. aeruginosa (ATCC 15442) was selected because it is specified by the AOAC for use-dilution tests. This strain as acquired from the American Type Culture Collection (ATCC; Manassas, VA). Bacteria from the stock culture were transferred into $10 \mathrm{~mL}$ tubes and incubated with nutrient broth (NB) at $36 \pm 1{ }^{\circ} \mathrm{C}$. Daily transfers were made for a minimum of three consecutive days. NB tubes $(20 \mathrm{~mL})$ were inoculated with one loop of inoculum per tube and incubated at $36 \pm 1^{\circ} \mathrm{C}$. After 48-54hours, the pellicle formed in the culture of $P$. aeruginosa was removed by gentle aspiration of the broth away from the pellicle, the cultures were used to contaminate the carriers. Each inoculum was agitated on a Vortex-type mixer for 3-4seconds, and then allowed to sit for ten minutes. The upper portion of each culture was removed, leaving any debris or clumps in the tube, and transferred to a sterile flask, pooled, and swirled to mix. Aliquots of $20 \mathrm{ml}$ were transferred into $25 \times 100 \mathrm{~mm}$ sterile tubes, with mixing of the inoculum between transfers.

\section{Carrier preparation}

Stainless steel carriers were soaked overnight in $1 \mathrm{~N}$ sodium hydroxide, rinsed with tap water until they reached a neutral $\mathrm{pH}$, and then rinsed twice with deionized water. The carriers were placed in multiples of 10 sterile tubes, covered with sterile deionized water, steam-sterilized for 20 minutes at $121^{\circ} \mathrm{C}$, cooled, and stored at ambient temperature until use. On the day of the test, the sterile deionized water from the carriers. The carriers were placed into growth broth and remained in contact with the inoculum (20 carriers per tube of $20 \mathrm{~mL}$ inoculum) for $15 \pm 2$ minutes at ambient temperature. Then they removed from the broth and placed in sterile Petri dishes, matted with filter paper, and dried at $36 \pm 1^{\circ} \mathrm{C}$ for $40 \pm 2$ minutes. For each group of ten test replicates, 11-12 carriers were added to a single Petri dish. For each group of 60 carriers, three carriers were randomly selected as carrier count controls and the remaining carriers were used for the viability controls.

\section{Use dilution studies}

The experimental design for the use-dilution studies followed the general procedure outlined in the AOAC Official Method 964.02. ${ }^{13}$ The tests were carried out at both ambient and accelerated temperatures, $20 \pm 1{ }^{\circ} \mathrm{C}$ and $45 \pm 1{ }^{\circ} \mathrm{C},{ }^{16}$ and the tubes containing test agent were maintained at the testing temperature throughout the test. One contaminated carrier was added to each tube and briefly swirled to mix (not shaken); the carrier remained in contact with the disinfectant for times ranging between one to twelve minutes. Thereafter, the carriers were removed, transferred to recovery broth with neutralizer, and the tubes were thoroughly shaken. All tubes were incubated at $36 \pm 1^{\circ} \mathrm{C}$ for $48 \pm 2$ hours, and the results were recorded as visible growth or no visible growth. According to the US regulatory authorities, the disinfectant passes the test if no visible growth is observed in at least 59 out of 60 subculture broth tubes and the controls meet their stipulated criteria. However, this threshold was recently relaxed by the US EPA to just 54 out of $60 .{ }^{17}$

Table 2 Product identifiers (lot number, source, and expiration date)

\begin{tabular}{llll}
\hline Product & Lot & Sourced from & $\begin{array}{l}\text { Expiration } \\
\text { date }\end{array}$ \\
\hline Microbide $^{\circledR}$-G & GSRW40-8296 & LPDS Ltd & $01 / 2015$ \\
Microbide $^{\circledR}-\mathrm{O}$ & GSRW40-8300 & LPDS Ltd & $01 / 2015$ \\
Cidex Plus $^{\mathrm{TM}} 28$ & 191211 & Allegro Medical & $12 / 2013$ \\
Cidex $^{\circledR}$ OPA & 070212104 & Allegro Medical & $02 / 2014$ \\
\hline
\end{tabular}




\section{Use dilution study controls}

Sterility control (SC): One tube of recovery broth with neutralizer containing a single sterile carrier was incubated with the test.

Neutralizer effectiveness (NE): For each disinfectant, two tubes containing $10 \mathrm{~mL}$ of the disinfectant were allowed to equilibrate to the testing temperature for at least ten minutes. A single sterile carrier was added to each tube and held for the same time as the test carriers. After the contact time, the carrier was added to each tube containing recovery broth with neutralizer. A low level (10-100 Colony Forming Unit (CFU)) inoculum of $P$. aeruginosa was added to each tube. The $\mathrm{CFU}$ added to each tube was confirmed in duplicate Nutrient Agar (NA) pour plates. The tubes and plates were incubated with the test.

Carrier counts (CC): The average CFU per carrier was determined using three inoculated carriers (one replicate from each group of ten carriers inoculated in a group of 11-12). Dried carriers were placed individually into tubes containing $10 \mathrm{~mL}$ of Letheen Broth. The tubes were subjected to ultrasound for 1 minute \pm 5 seconds in a cleaning sonicator. Serial 10-fold dilutions of each suspension were performed in phosphate-buffered saline blanks. Duplicate $1 \mathrm{~mL}$ aliquots from selected dilutions were plated in NA pour plates. All plates were incubated with the test and the average CFU/carrier was determined.

Viability controls (VC): Two inoculated carriers were inoculated into tubes of recovery broth with neutralizer. These were incubated with the test for comparison with the test cultures.

Bacteriostasis controls (BC): If after two days of incubation, no growth was observed in any of the test tubes, $20 \%$ of the tubes were streaked onto tryptic soy agar (TSA) plates and incubated for $24 \pm 2$ hours at $36 \pm 1^{\circ} \mathrm{C}$. No growth on these plates negated bacteriostasis as the cause for lack of growth.

Confirmation of challenge microorganism: For each challenge microorganism, all of the viability controls and at least $20 \%$ of the test tubes showing growth were streaked onto TSA and incubated for $24 \pm 2$ hours at $36 \pm 1^{\circ} \mathrm{C}$. Gram stains of the streaks were performed to confirm growth of the challenge microorganism.

\section{Results}

\section{Bactericidal efficacy and contact time-dependence at $20 \pm 1^{\circ} \mathrm{C}$}

The bactericidal efficacies of Microbide-O, Cidex ${ }^{\circledR} \mathrm{OPA}$, Microbide-G, and Cidex Plus ${ }^{\mathrm{TM}} 28$ for preventing the growth of $P$. aeruginosa were evaluated at ambient temperature $\left(20^{\circ} \mathrm{C}\right)$. Contact time-dependent bactericidal activity was observed for each of the four disinfectants. All four disinfectants passed the test at both temperatures tested (Table 3). However, differences between the various disinfectants were noted in regard to required contact time: Microbide-G achieved full disinfection of all 60 carriers after three minutes of contact time; the other three disinfectants - Cidex Plus $^{\mathrm{TM}}$ 28, Cidex ${ }^{\circledR} \mathrm{OPA}$, and Microbide-O-reached full disinfection status after twelve minutes of contact time at ambient temperature. Assuming a fail threshold of $1 / 60$, Cidex Plus ${ }^{\mathrm{TM}} 28$ failed at three and five minutes contact time at ambient temperature; $\mathrm{Cidex}^{\circledR} \mathrm{OPA}$ failed at five and eight minutes; and Microbide-O failed at five minutes.

Table 3 Disinfectant comparison - AOAC use dilution test results for Microbide-G versus Cidex Plus ${ }^{\mathrm{TM}} 28$ and Microbide-O versus Cidex ${ }^{\circledR} \mathrm{OPA}$ against Pseudomonas aeruginosa

\begin{tabular}{|c|c|c|c|c|c|c|c|c|c|}
\hline \multicolumn{2}{|c|}{$\begin{array}{l}\text { Contact } \\
\text { Temperature \& } \\
\text { Time }\end{array}$} & \multicolumn{2}{|c|}{$\begin{array}{l}\text { Test tube results } \\
\text { Positive Total Evaluated }{ }^{\dagger}\end{array}$} & \multicolumn{2}{|c|}{$\begin{array}{l}\text { Average carrier counts } \\
\text { (CFU carrier average of } 3 \text { replicates) }\end{array}$} & \multicolumn{2}{|c|}{$\begin{array}{l}\text { Test tube results } \\
\text { Positive Total Evaluated }{ }^{\dagger}\end{array}$} & \multicolumn{2}{|c|}{$\begin{array}{l}\text { Average carrier counts } \\
\text { (CFU carrier average of } 3 \\
\text { replicates) }\end{array}$} \\
\hline \multirow{3}{*}{$\begin{array}{l}\text { Temp } \\
(+/- \\
\left.1^{\circ} \mathrm{C}\right)\end{array}$} & Time & CidexPlus 28 & Microbide-G & CidexPlus 28 & Microbide-G & Cidex OPA & Microbide -O & Cidex OPA & Microbide -O \\
\hline & (min) & $\begin{array}{l}(3.4 \% \\
\text { glutaraldehyde) }\end{array}$ & $\begin{array}{l}\text { (3.0\% micellar } \\
\text { glutaraldehyde) }\end{array}$ & $\begin{array}{l}(3.4 \% \\
\text { glutaraldehyde) }\end{array}$ & $\begin{array}{l}\text { (3.0\% micellar } \\
\text { glutaraldehyde) }\end{array}$ & $\begin{array}{l}(0.55 \% \\
\text { OPA })\end{array}$ & $\begin{array}{l}(0.55 \% \text { micellar } \\
\text { OPA })\end{array}$ & $(0.55 \%$ OPA $)$ & $\begin{array}{l}\text { (0.55\% micellar } \\
\text { OPA) }\end{array}$ \\
\hline & 12 & $0 / 60$ & $0 / 60$ & $7.1 \times 10^{6}$ & $6.5 \times 10^{6}$ & $0 / 60$ & $0 / 60$ & $3.3 \times 10^{6}$ & $3.3 \times 10^{6}$ \\
\hline & 8 & $1 / 60$ & $0 / 60$ & $7.2 \times 10^{6}$ & $8.2 \times 10^{6}$ & $2 / 60^{*}$ & $1 / 60$ & $5.8 \times 10^{6}$ & $5.9 \times 10^{6}$ \\
\hline & 5 & $2 / 60 *$ & $0 / 60$ & $6.2 \times 10^{6}$ & $6.2 \times 10^{6}$ & $5 / 60 *$ & $4 / 60 *$ & $5.9 \times 10^{6}$ & $3.1 \times 10^{6}$ \\
\hline & 3 & $4 / 60 *$ & $0 / 60$ & $7.9 \times 10^{6}$ & $8.6 \times 10^{6}$ & & & & \\
\hline & 5 & & & & & $0 / 60$ & $0 / 60$ & $1.1 \times 10^{6}$ & $3.0 \times 10^{6}$ \\
\hline & 3 & $0 / 60$ & $0 / 60$ & $8.5 \times 10^{6}$ & $8.2 \times 10^{6}$ & $2 / 60 *$ & $0 / 60$ & $2.9 \times 10^{6}$ & $2.9 \times 10^{6}$ \\
\hline \multicolumn{10}{|l|}{$45^{\circ} \mathrm{C}$} \\
\hline
\end{tabular}

${ }^{\dagger}$ To pass the test, the disinfectant must achieve no growth in all 60 replicates or a $95 \%$ confidence interval with only 1 positive among 60 replicates. *Failures are denoted by an asterisk. 


\section{Bactericidal efficacy and contact time-dependence at $45 \pm 1^{\circ} \mathrm{C}$}

Under increased temperature, the bactericidal effects of all disinfectants were enhanced (Table 3). Microbide-G passed after one minute of contact time, whereas Cidex Plus ${ }^{\mathrm{TM}} 28$ failed with growth in three tubes. Microbide-O passed at three minutes of contact time, whereas $\mathrm{Cidex}^{\circledR} \mathrm{OPA}$ failed with growth in two tubes. Eventually, all disinfectants achieved complete disinfection at $45^{\circ} \mathrm{C}$ : Cidex Plus ${ }^{\mathrm{TM}}$ 28, Microbide-G, and Microbide-O after three minutes of contact time, whereas $\mathrm{Cidex}^{\circledR} \mathrm{OPA}$ required five minutes of contact time.

\section{Controls}

All of the controls met the criteria established for a valid test (Table 3).

\section{Discussion}

Targeting P. aeruginosa in disinfectant studies is essential because of its high prevalence in hospital-acquired infections. The Health Canada guidance documents Safety and Efficacy Requirements for Hard Surface Disinfectant Drugs ${ }^{18}$ and Human-Use Antiseptic Drugs ${ }^{19}$ specify $P$. aeruginosa as one of the model organisms to be used to determine an acceptable level of bactericidal efficacy. Additionally, the CDC Guidelines for Disinfection and Sterilization in Healthcare Facilities $^{9}$ state that $P$. aeruginosa is one of the organisms that may be used as a model bacterium for determining acceptable bactericidal efficacy of disinfectants in all hospitals. The ability of chemical disinfectants to meet efficacy requirements for killing $P$. aeruginosa helps to assure that these disinfectants will provide adequate safety for patients admitted to a hospital. Therefore, the pass-threshold of disinfectants intended to act against this model bacterium should be high. However, the performance standard pass-threshold was lowered in 2013 following consultation with the EPA and industry members. ${ }^{17}$ Taking into account the revised procedure, all of the four disinfectants would have passed at all contact-times tested. This discrepancy further increases the difficulty for hospital personnel responsible for infection control to differentiate between various medical protocols. Therefore, this paper uses the original, stricter guidelines for clarification purposes.

Aldehydes, such as glutaraldehyde, are commonly used for highlevel disinfection of medical instruments, such as endoscopes, that may be damaged by alternative chemical or physical approaches due to their complex construction with multiple parts and materials. ${ }^{20} \mathrm{In}$ 2002, the United Kingdom's National Health Service (NHS) started phasing out glutaraldehyde-based disinfectants after the Health \& Safety Executive concluded that it was the $5^{\text {th }}$ highest cause of occupational asthma. ${ }^{21}$ Microbide's proprietary micellization process develops products that have largely abated the respiratory exposure issues, extended the product's shelf-life, rendered the product biodegradable, and increased the efficacy of the disinfectant; thereby leading to faster, safer, and complete disinfection. ${ }^{22}$ Microbide has used micellization in the manufacture of its products to allow disinfectant to be at a higher energy level at neutral $\mathrm{pH}$, and to retain its activity by surrounding the disinfecting aldehyde with a micelle of nonionic surfactant. This process reduces volatility, thereby reducing exposure of the operator - qualitatively, numerous technicians reported that Microbide-G was less noxious than Cidex Plus $^{\mathrm{TM}} 28$. Furthermore, micellization increased time for disinfection of environmental surfaces, and enhanced shelf-life. The micelle also points the disinfectant's active moiety toward the surface, thereby enhancing the aldehyde's ability to interact with nitrogen-containingamino acids on the bacterial surface.

Microbide-G outperformed Cidex Plus ${ }^{\mathrm{TM}} 28$ at both temperatures, although Cidex Plus ${ }^{\mathrm{TM}} 28$ was used at a higher concentration of glutaraldehyde than Microbide-G (3.4\% vs 3.0\%, respectively). The test showed that Microbide-G successfully disinfected more carriers than Cidex Plus ${ }^{\mathrm{TM}} 28$ and was also more effective at shorter contact times. The behavior of Microbide- $\mathrm{G}$ as an effective viral disinfectant has also been documented against Porcine Parvovirus and Poliovirus Type-1 as surrogates for viruses. ${ }^{23,24}$ Unlike Clorox and hypochlorite products that can be inactivated by organic loads harboring a virus, the micellar di-aldehydes (such as Microbide-G) were superior at neutralizing viruses on fomites. Additionally, at near neutral $\mathrm{pH}$ values, these products are unlikely to harm surfaces. Another relevant aspect that affects the disinfection process is $\mathrm{pH}$. Glutaraldehyde increases in biocidal efficacy with an increase in $\mathrm{pH}$. The $\mathrm{pH}$ of all disinfectants was recorded after dilution and is shown in Table 1. Microbide-G was $\mathrm{pH}$-stressed $(\mathrm{pH}=6.4)$ at a level well below the manufacturer's intended use at near neutral $\mathrm{pH}$; therefore, we expect that if maintained at $\mathrm{pH} 7.7$ (equivalent to Cidex Plus ${ }^{\mathrm{TM}} 28$ ), biocidal capacity will be further enhanced.

As an alternative to the sterilant glutaraldehyde, products containing the less high-level disinfectant ortho-phthalaldehyde are thought to be safer, having similar disinfectant properties with less health risks to repurposing personnel due to its lower vapor pressure and lower toxicity levels. ${ }^{25}$ However, recent research has raised new toxicity concerns for ortho-phthalaldehyde as a substitute, ${ }^{26}$ because its adhesive nature has led to reports of anaphylactic shock from residual on endoscopes..$^{27}$ The micellized nature of Microbide's products eliminates adhesion, and thus, demonstrates clear advantages for infection control. Microbide-O outperformed Cidex ${ }^{\circledR} \mathrm{OPA}$ at both temperatures by successfully disinfecting more carriers overall and failing just one test compared to $\mathrm{Cidex}^{\circledR} \mathrm{OPA}$, which failed three tests (Table 3). Each of the four disinfectants evaluated in this study were effective as biocides against $P$. aeruginosa; however, the Microbide products required less time for complete disinfection and were more consistent in their efficacy (Table 3). When considering the use of highly efficacious cleaning products against nosocomial infections, it is important to think of these products in the context of their usage. Wider biological and practical considerations are often ignored in use-dilution studies because of the focus on efficacy. The micellization process used by Microbide lowers the vapor pressure, and thus, the volatility of the molecules involved. This characteristic - in combination with the short time period required for complete disinfection - assures that the surfaces to be disinfected remain wet during the application. The reduced vapor pressure further increases safety, stability, and shelf-life of the products. Cidex ${ }^{\circledR} \mathrm{OPA}$ is only indicated as a high-level disinfectant for semi-critical medical devices, but not for the sterilization of invasive medical instruments, whereas Cidex Plus ${ }^{\mathrm{TM}} 28$ is indicated for both applications. ${ }^{28}$ Both Microbide-O and Microbide-G are being considered for registration as high-level disinfectants and as sterilizing agents. ${ }^{22}$

\section{Conclusion}

All four products analyzed in this study fulfill the requirements set by the FDA for high-level disinfectants. However, complete bactericidal efficacy at $20^{\circ} \mathrm{C}$ was observed with Microbide-G after just three minutes of contact time, whereas the other glutaraldehydecontaining product, Cidex Plus ${ }^{\mathrm{TM}} 28$, required an additional nine 
minutes. At $20^{\circ} \mathrm{C}$, Microbide-O outperformed the other orthophthalaldehyde-containing product, Cidex ${ }^{\circledR} \mathrm{OPA}$, at every contact time point. At $45^{\circ} \mathrm{C}$, the pattern was similar with the Microbide products passing all tests, whereas the Cidex products each failed at one of the two time points. Several elements should be deliberated when differentiating between disinfectants, such as time required to complete disinfection, cost, convenience of usage, and toxicity to personnel. Considering these factors, and interpreting the results of this study, the enhanced speed of action and efficacy of Microbide-G and Microbide-O show them to be far superior for practical and safe hospital usage than the current market leaders.

\section{Declarations}

\section{Funding}

Funding for the use-dilution studies described herein was provided by Microbide Limited (Dublin, Ireland).

\section{Authors' contributions}

LMG interpreted the results, researched and wrote the paper; ALH was the laboratory study director and oversaw the laboratory tests; DBS provided invaluable advice on the planning and interpretation of this study. All authors read and approved the final manuscript.

\section{Conflicts of interest}

LMG has consulted for and been remunerated by Microbide Limited. DBS is part of the scientific advisory board for Microbide Limited.

\section{Acknowledgments}

Rolf König provided a language editing service. Siddharth Dutta consulted on publication

\section{References}

1. Trautmann M, Lepper PM, Haller M. Ecology of Pseudomonas aeruginosa in the intensive care unit and the evolving role of water outlets as a reservoir of the organism. Am J Infect Control. 2005;33(5):S41-S49.

2. Struelens MJ, Rost F, Deplano A, et al. Pseudomonas aeruginosa and Enterobacteriaceae bacteremia after biliary endoscopy: An outbreak investigation using DNA macrorestriction analysis. $\mathrm{Am} \mathrm{J} \mathrm{Med}$. 1993;95(5):489-498.

3. DiazGranados CA, Jones MY, Kongphet-Tran T, et al. Outbreak of Pseudomonas aeruginosa infection associated with contamination of a flexible bronchoscope. Infect Control Hosp Epidemiol. 2009;30(6):550-555.

4. Kolmos HJ, Thuesen B, Nielsen SV, et al. Outbreak of infection in a burns unit due to Pseudomonas aeruginosa originating from contaminated tubing used for irrigation of patients. J Hosp Infect. 1993;24(1):11-21.

5. Bailey CR. An outbreak of Pseudomonas aeruginosa infections associated with flexible bronchoscopes. Survey Anesthesiol. 2004;48(1):33-34.

6. Centers for Disease Control and Prevention. Pseudomonas aeruginosa in healthcare settings. 2018

7. Whiteley M, Bangera MG, Bumgarner RE, et al. Gene expression in Pseudomonas aeruginosa biofilms. Nature. 2001;413(6858):860-864.

8. Livermore DM. Multiple mechanisms of antimicrobial resistance in Pseudomonas aeruginosa: Our worst nightmare? Clin Infect Dis. 2002;34(5):634-640.
9. Centers for Disease Control and Prevention. Guidance document Disinfection and sterilization in healthcare facilities. 2008.

10. Quinn MM, Henneberger PK, Braun B, et al. Cleaning and disinfecting environmental surfaces in health care: Toward an integrated framework for infection and occupational illness prevention. Am J Infect Control. 2015;43(5):424-434.

11. Best M, Springthorpe VS, Sattar SA. Feasibility of a combined carrier test for disinfectants: Studies with a mixture of five types of microorganisms. Am J Infect Control. 1994;22(3):152-162.

12. Reybrouck $\mathrm{G}$. The testing of disinfectants. Int Biodeterior Biodegradation 1998;41(3-4):269-272.

13. Tomasino S. AOAC official method 964.02: testing disinfectants against Pseudomonas aeruginosa use-dilution method. In: Latimer GW, editor. 19th edn. Gaithersburg, MD: AOAC International; 2013.

14. US Environmental Protection Agency. Office of Pesticide Programs. Standard operating procedure for AOAC use-dilution method for testing disinfectants. 2016.

15. Tomasino SF, Parker AE, Hamilton MA, et al. Performance of the AOAC use-dilution method with targeted modifications: collaborative study. $J$ AOAC Int. 2012;95(6):1618-1628.

16. Janowska J, Krzywicka H, Zarzycka E. The effect of temperature on bactericidal activity of certain disinfectants. Rocz Panstw Zakl Hig. 1994;45(3):237-240.

17. Office of Pesticide Programs. Revisions to the performance standard for the AOAC use-dilution methods for Staphylococcus aureus (955.15) and Pseudomonas aeruginosa (964.02). US Environmental Protection Agency. 2013.

18. Health Canada. Guidance document - safety and efficacy requirements for hard surface disinfectant drugs. 2014.

19. Health Canada. Guidance document - human-use antiseptic drugs. 2009.

20. Rutala W. APIC guideline for selection and use of disinfectants. Am J Infect Control. 1996;24(4):313-342.

21. Niven K. An evaluation of chemical disinfecting agents used in endoscopy suites in the NHS. Norwich, UK. Health \& Safety Executive; 2006.

22. Microbide. High-level disinfectants. 2018.

23. Lukula S, Chiossone C, Fanuel S, et al. Inactivation and disinfection of porcine parvovirus on a nonporous surface. J Microb Biochem Technol. 2017;9(5):232-236.

24. Chiossone C, Fanuel S, Gedge LM, et al. Inactivation and disinfection of Poliovirus type 1 on nonporous carriers. Adv Biotechnol Microbiol. 2018;9(5):555773.

25. Park S, Jang JY, Koo JS, et al. A review of current disinfectants for gastrointestinal endoscopic reprocessing. Clin Endos. 2013;46(4):337.

26. Catlin NR, Willson CJ, Stout M, et al. Evaluation of the respiratory tract toxicity of ortho-phthalaldehyde, a proposed alternative for the chemical disinfectant glutaraldehyde. Inhal Toxicol. 2017;29(9):414-427.

27. Atiyeh K, Chitkara A, Achlatis S, et al. Allergic reaction to orthophthalaldehyde following flexible laryngoscopy. Laryngoscope. 2015;125(10):2349-2352.

28. U.S. Food \& Drug Administration. FDA-cleared sterilants and high level disinfectants with general claims for processing reusable medical and dental devices. 2015. 